\title{
Multicultural Education Practices in Malaysian Preschools with Multiethnic or Monoethnic Environment
}

\author{
Najeemah Mohd Yusof*; Anna Christina Abdullah; Norlida Ahmad \\ Email: najineen@usm.my
}

\begin{abstract}
In today's increasingly diverse world, ethnicity has a dramatic impact on a growing child. The 'melting pot' concept has given children whether from majority or minority ethnic groups have contact with groups other than their own and must learn to live with ethnic diversity. Ethnic diversity affects social interaction among students of different ethnic groups. Social interaction among students of different ethnic groups has been a major focus of study in Malaysia in recent years. Schools in Malaysia have students from a variety of ethnic, linguistic, religious and cultural backgrounds. When students of a variety of backgrounds are put under one roof, there is a strong tendency to differentiate and polarize. One of the main causes for students to differentiate and polarize is due to the monoethnic environment. Preschools must begin a focused and concerted effort to provide for today's children the skills, attitudes, and knowledge they will need to be successful in the pluralistic and interdependent world in which these children will live and work as adults. Among these competencies are the ability to be multilingual and the ability to be cross-culturally competent. A multicultural classroom, then, is one that features positive teacher expectations for all children, a learning environment that supports positive interracial contact, and a curriculum that is multicultural in content and varied in pedagogy. This article will discuss Multicultural Education Practices by teachers in Malaysian Preschools with a multiethnic or monoethnic environment. A study was conducted in 200 preschools in North Malaysia. The nature of multicultural education in this study is classified according to an instrument which is related to the children's' lives. The teachers were given a set of questionnaires and findings were analyzed quantitatively.
\end{abstract}

Keywords: Multicultural Education, Preschool, Monoethnic, Multiethnic, Environment

\section{Introduction}

Most large societies often have subcultures or groups of people with distinct sets of behavior and beliefs that differentiate them from a larger culture of which they are a part. The subculture may be different because of the age of its members, or by their race, ethnicity, or class. The qualities that determine a subculture as distinct may be aesthetic, religious, occupational, political, sexual or a combination of these factors. At first glance, it may seem that only in countries such as Malaysia whose population is made up many different cultural communities that the issue of multicultural education seems pertinent. However with the phenomenon of transmigration, the world becoming a borderless village, increasing 
interdependence among countries, and more tragic and spectacular events like 9/11 and the ominous threat of the 'clash of the civilizations', the issue of multiculturalism and its place in education is becoming more important. A deliberate and conscious effort has to be undertaken to promote respect and not just mere tolerance for differences, including cultural ones which make up the most contentious of differences amongst mankind. Culture is after all the sum total of what makes one distinct from others of a different culture. If mankind is to live in harmony and goodwill, then they have to come to terms with these differences. Coming to terms will need education, and the best time to start with this education is right from the start in early childhood.

\section{Statement of the Problem}

The past decade has witnessed heightened awareness of the increasing social divide between the different racial groups in Malaysia, especially in schools and higher education institutions. Many reasons have been suggested for the lack of interaction between these groups of youth which not only is evident among the main ethnic groups, but also occurs across state or regional divides (e.g. undergraduates in universities tend to mingle more with those from the same state or district). One very strong explanation for this phenomena is, of course, the pattern of student enrollment in schools which sees mainly Malays in national and residential schools, whilst the majority of Chinese students are enrolled in the National-type schools. In schools pupils in primary right up to secondary levels too tend to socialize more with peers of similar ethnic or cultural background. Because of this sad state of affairs some efforts have been made to try to stop this trend from worsening. Some of the initiatives taken were to encourage the involvement of more non-Malays in traditionally Malay dominated school societies, and vice-versa, the banning of race and state-based student societies in universities, the introduction of national service, the introduction of the 'ethnic relations' module as a compulsory course to be taken by all undergraduates etc.

However as with most, if not all behavioral changes, the earlier we nurture and shape these intended outcomes in the child the more effective and sustainable it becomes. I would regard the above initiatives as coming too late in the development of the individual. Early childhood research has shown that there are window periods for particular types of learning.

More specifically, brain research has shown that the "prime time" for emotional and social development in children is birth to 12 years of age. Differing aspects of emotional and social development, which incorporate higher capacities, such as awareness of others, empathy and trust, are important at different times. Emotional intelligence is critical to life success. The part of the brain that regulates emotion, the amygdala, is shaped early on by experience and forms the brain's emotional wiring. Early nurturing is important to learning empathy, happiness, hopefulness and resiliency. Social development, which involves both self-awareness and a child's ability to interact with others, also occurs in stages. The caregiver's efforts to nurture and guide a child will assist in laying healthy foundations for social and emotional development. Additionally, it is important that we catch them young, when the likelihood of them having been socialized or enculturated with negative stereotypes and biases is less. Children also are capable of being 'teachers' or influencing adults when they transfer what they learn in early childhood care centres. Children have been known to reprimand their smoker-parents that 'smoking is bad and it can kill you'. Similarly if and when they hear negative comments about culturally different people coming from their parents or older siblings, they can then either correct their perceptions or ask why they say these things, and therefore perhaps even get them to re-examine their prejudices.

Thus, it is vital that this study be conducted to examine systematically whether such nurturing is being carried out in early childhood education (preschools). In the process of doing so, this study will also be able to inform us whether present practices are adequate enough, and if not, then we will be able to recommend changes that will put in place policies, philosophies, strategies and procedures that will ensure that multicultural education is being implemented appropriately. 


\section{Literature Review}

\section{Children and Bias}

Most people assume that children in their early years are still innocent and do not have negative attitudes towards people who are different from them. There are also suggestions that multicultural education should be reserved for older children who are less egocentric or ethnocentric. Lynch and Hanson (1998) tell us that "cultural understanding in one's first culture occurs early and is typically established by age 5" (p. 24). They go on to say, "Children learn new cultural patterns more easily than adults" (p. 25). Young children are capable of learning that we are all alike and all different in certain way. In fact, research has also demonstrated that children are not totally free of bias and prejudice. Studies (Glover, 1996; Ramsey \& Myers, 1990; Palmer, 1990) have shown that children as young as three notice differences such as skin, eye and hair colour. As part of their socialisation, children develop their self-identity by comparing their own selves with others. They learn that they belong to certain groups and not to others due to certain visible similarities and differences. Through observing how others around them react and respond to these differences, they see what is valued and what is not. They start to develop positive or negative feelings about the differences observed. These feelings form the basis of evaluative judgments whether these differences are 'good' or 'bad'. These judgments then become their bias and prejudice if framed in negative terms. For example, children exhibit preferences for same-race when selecting dolls, refusing to hold different-race children's hands (Glover, 1991). The influence of family, significant others, early childhood services, and the mass media play a vital role in developing children's attitudes and behaviours towards differences. Children learn to treat others differently on the basis of race, gender, age, ability, religion and cultural heritage either directly or vicariously through the gradual process of socialisation and enculturation.

\section{Provisions for Multicultural Education}

\section{Access}

Early Childhood Australia National Council (2007) have advocated the following provisions to be made policy with regards access to services in early childhood that ensures multiculturalism is respected:

o Childhood services which support their cultural identity and their community.

o Services are be planned, implemented and evaluated through ongoing discussion with service users and the wider community to reflect the diversity of that community.

o Within each service information is provided in a variety of ways, for example oral, visual and written.

o Information about the service for families is accessible. This is facilitated by multilingual translations and/or interpreter services relevant to the families.

o Families who are disadvantaged by the particular circumstance of recent arrival in the country or community are provided with special consideration regarding access and support.

\section{Curriculum}

Other than policy, provisions related to actual curricular practices and processes need also to be looked into (National Association for the Education of Young Children, 2007; Robinson \& Jones Diaz, 2006; Stonehouse, 2002). Among the aspects included would be: 
o Children in the classroom are seated or carry out their activities in mixed (ethnic/cultural) groupings if possible

o Posters, books, CDs, images, songs and other resources used in either the classroom or playroom setting represent realistic linguistic, cultural and social practices of the children.

o Stereotypic images are avoided and there is a careful balance of resources that represent both traditional and contemporary images of cultural and language practices.

o Texts in children's languages, including books, newspapers, games, electronic media and popular culture texts are used throughout the day across different curriculum areas.

o Programs provide opportunities for all children, staff and families to use a variety of communication forms including languages other than the majority language. (The provision for language development will be discussed in greater detail in the next section).

o Programs reflect the diversity of cultures represented by the broader community and extend both children's knowledge of their own culture and knowledge of cultures other than their own.

o Programs, policies, practices and curricula are not only culturally inclusive but consciously work to recognise and take action against bias, combat racism and reject stereotyping.

o Parents and community are consulted in developing programs and value differences are clearly identified and discussed.

\section{Language}

Another important ingredient which can actually be subsumed in the curricular category above is language development. It is treated separately here as it plays a very significant part in early childhood development. Generally, the educational system in most countries utilises the national language (usually the majority language) as the medium of instruction. However multiculturalism and the recognition of the pivotal role of language in learning makes it obligatory for a diversity of language, literacies and communication styles to be recognised, valued and used within all early childhood services. The provision for children to learn the majority language whilst maintaining their first language should be supported and encouraged. This of course is to propose bilingualism or at least support for the home language as a policy even at the early childhood education level. Research has shown that there can only be advantages to the child besides protecting and respecting the home language. For example, Since the 1960s, research has shown that multiple language skills do not confuse the mind. Quite the contrary: when well-developed, they seem to provide cognitive advantages, although such effects are complex and difficult to measure (Hakuta, 1986).

\section{Early Childhood Education Staff}

Finally and not the very least, is the very important prerequisite of early childhood education staff, i.e. their recruitment and professional development. Few can deny that apart from their own family, staff working in children's services potentially impact on children's developing attitudes towards cultural diversity more than any other persons in a child's life. Therefore, it is essential that staff undergo and receive appropriate training or staff development programs which incorporate the necessary knowledge, skills and attitudes for such a responsibility. In countries that have a well developed early childhood education system in place, most staff if not all would have acquired a minimum standard of qualification 
before they can be recruited into the service. However for those countries who have only just recognized the importance of having a strong foundation by having quality early childhood education, like Malaysia, the picture might not be as encouraging. It is possible that many staff would only have had high school education or less, without any specialized training in early childhood education.

Education courses for early childhood personnel should have elements in both content and delivery that address diversity of cultures. Pre-service preparation in the form of authentic situations where student teachers are placed in multicultural or classrooms made up of cultures different from their own are especially effective in getting teacher candidates to re-examine their existing beliefs and preconceptions. For example, Baldwin et al. (2007:326) reports that servicelearning (collaborative community-based practicum)

“....positively affects teacher candidates' dispositions toward teaching in diverse settings. Teacher candidates learned about diversity and even began to question societal inequities that they encountered. Service-learning has the potential of empowering teacher candidates to confront difficult issues of societal inequities and to begin the deconstruction of lifelong attitudes and the construction of socially just teachers".

Courses need to recognize and reflect differing beliefs about childhood held by different cultures. Within relevant courses, particular emphasis is to be given to the understanding of how children develop language, and teachers ought to be provided practical experiences in teaching a second language. Besides pre-service training, continuing education on multicultural and indigenous issues should be made readily available for all staff working with young children. Service staffs are to be assisted to engage in professional development, which enables them to examine their own values and assumptions in relation to race, culture, class, sexuality and gender and the impact these may have on their practice. Once again, this provision will differ depending on the state of development of early childhood education in that country. Additionally the commitment to staff's continuing professional development will also be dependent on the centres' own philosophy and belief in this critical pedagogy and reflective practice which underlies an authentic perspective of diversity.

\section{Multicultural Education in Early Childhood Settings}

Most of the current literatures of multicultural education in early childhood settings come from the United States. Bruch et al. (2004) identified three dominant approaches which are used, the 'celebratory', the 'critical' and the 'transformative' approaches. The celebratory approach moves away from defining differences as deficiencies to highlighting the positive accomplishments and aspects of different cultures and social groups. The critical approach examines and challenges issues of power and privilege in society, confronts racism and other biases; whilst the transformative approach seeks to find ways to transform domination for the good of all as a means of improving society and the world. In taking a multicultural perspective in early childhood education, Gonzalez-Mena (2000) reminds us that practitioners must not forget to treat the dominant culture also as a culture, and not as a universal reality. When the dominant culture is not named as such, the insinuation is that the dominant culture is 'normal' and that the other cultures are deviations from the norm.

Another advocate of multicultural education (Banks, 1994) offers different though quite similar suggestions for how it can be accomplished in school practice. Banks suggested four approaches to multicultural education, each increasingly more significant and comprehensive: (1) teaching about contributions of culturally different groups and individuals; (2) an additive approach in which multicultural lessons and units of study are supplements or appendages to existing curricula; (3) a transformation approach in which the basic nature of curriculum and instruction are changed to reflect the perspective and experiences of diverse cultural, ethnic, racial, and social groups; and (4) a decision 
making and social action approach that teaches students how to clarify their ethnic and cultural values, and to engage in socio political action for greater equality, freedom, and justice for everyone. Others however, prefer to take a more holistic approach to multicultural education by advocating an anti-bias curriculum (Hohensee \& Derman-Sparks, 1992). An anti-bias curriculum seeks to nurture the development of every child's fullest potential by actively addressing issues of diversity and equity in the classroom. Specific goals of an anti-bias curriculum are to foster each child's: construction of a knowledgeable, confident self-identity; comfortable, empathic interaction with people from diverse backgrounds; critical thinking about bias; and an ability to stand up for herself or himself, and for others, in the face of bias.

It will be interesting to see if any of the above approaches are being used in our preschools. This study will be able to shed light on this matter, as well as delve deeper into the rationale and philosophy underlying the approaches utilized in the respective settings.

\section{Objective(s) of the Research}

Research Objectives:

1. To investigate the state-of-practice of multicultural education in multiethnic and monoethnic environment preschools found in Malaysia.

2. To identify the similarities and differences in the practices of multicultural education in the different early childhood settings?

3. To identify the issues and challenges facing early childhood care providers in implementing multiculturalism in in a monoethnic and multiethnic environment.

\section{Research Questions:}

1. What is the state-of-practice of multicultural education in multiethnic and monoethnic environment preschools found in Malaysia.

2. What are the similarities and differences in the practices of multicultural education in the different early childhood settings?

3. What are the issues and challenges facing early childhood care providers in implementing multiculturalism in in a monoethnic and multiethnic environment?

\section{Methodology}

\section{Research Design}

This study is predominantly a survey utilizing self-report questionnaire. Nevertheless, it will also incorporate a qualitative component whereby more in-depth data will be gathered by means of interviews and observations. 


\section{Population and Sampling}

As at 2005, the number of preschool classes recorded (including government, quasi-government and private centres) was 26,859 and number of teachers stood at 34,526. The number of preschools was 16,397 with an enrolment of 703,017 (MoE, 2006). For this study the target sample size for the questionnaire survey will be $10 \%$ of the population with an expected return rate of $50 \%$. To ensure representation of all categories of preschools, random stratified sampling will be carried out.

Sampling of training institutions for data on teacher training programs will include all (100\%) institutions which offer the relevant diploma or degree courses.

\section{Research Instruments and Data Gathering}

The main tool for data collection will be self-report questionnaire to be administered to teachers, principals and teacher educators. These questionnaires would be the main means of gathering data related to policy and curriculum provisions, as well as teacher training and recruitment. Information on official policy would also be obtained from official documents of the relevant departments and agencies.

The quantitative data will be analysed mainly by descriptive statistics using SPSS package version 12.0.

\section{Findings}

The findings will be discussed according to the research questions.

\section{What Is the State-of-Practice of Multicultural Education in Multiethnic and Monoethnic Environment Preschools Found in Malaysia?}

From the research it found that teachers practice multicultural aspects whether it is a monoethnic or multiethnic environment preschool. About $85 \%$ of the teachers understand the idea of multicultural education even though they were not provided training pertaining to multicultural education/practices. As Banks (1994) point out, the increasing diversity in preschools presents challenges as well as opportunities. Educators must respect and build upon the cultural strengths and characteristics that children bring into the classroom. At the same time, educators must help all children acquire the knowledge, skills, and values needed to become active and productive members of our society. A teacher is a cultural mediator and an agent for change so they play a vital role. From the research it was found that educators from both the monoethnic and multiethnic environment preschools believe that an important goal of the preschools should be to forge a common nation and destiny from the tremendous ethnic, cultural, and language diversity. To forge a common destiny, educators must respect and build upon the cultural strengths and characteristics that children from diverse groups bring to preschool. At the same time, educators must help all students acquire the knowledge, skills, and values needed to become participating citizens of Malaysia. Cultural, ethnic, and language diversity provide the nation and the preschools with rich opportunities to incorporate diverse perspectives, issues, and characteristics into the nation and the preschools in order to strengthen both irrespective of the environment. Even though preschool children in monoethnic preschools only mingle with the same ethnic group, educators, are aware of this, about $95 \%$ include experiences that allow children to explore events, concepts, issues, and themes from multiple perspectives. These perspectives over time should be broad so that children don't end up inadvertently creating new stereotypes of different groups. Primary sources in the voices of the 
people they represent are used as frequently as possible. Such an approach will help children to understand that one issue or event can be viewed in different ways by different people.

\section{What Are the Similarities and Differences in the Practices of Multicultural Education in the Different Early Childhood Settings?}

From the research there were more similarities than differences in the practice of multicultural education in a monoethnic or multiethnic environment. It is rare that any two-classroom teachers will have the same definition for multicultural education. The basic goal of multicultural education is to help all children understand and appreciate events and people from various points of view. Teaching with a multicultural perspective encourages appreciation and understanding of other cultures as well as one's own. Rey Gomez states that teaching with this perspective promotes the child's sense of the uniqueness of his own culture as a positive characteristic and enables the child to accept the uniqueness of the cultures of others. Children's attitudes toward their race and ethnic group and other cultural groups begin to form early in the preschool years. Children are easily influenced by the cultural, opinions, and attitudes of their educators. Educators' perceptions of ethnic and racial groups can affect the child's attitudes toward those minority groups. Early childhood educators can influence the development of positive attitudes in young children by learning about and promoting the various cultures represented among the children they teach.

Teachers from monoethnic preschools, about $85 \%$, considered practical limitations, such as available resources, than did their colleagues from multiethnic preschools. Teachers from both monoethnic or multiethnic environment considered their education and training an important influence on teaching. Among the teachers, education/training was the most important factor. Also, while conceptions of multicultural education practice /teaching - including child-initiated learning, teacher-directed instruction of skills and integrated curriculum - seem to be similar in the monoethnic and multiethnic environment and the extent to which teachers endorse particular beliefs show no contrasts. Moreover, teacher characteristics, such as amount and type of professional education completed, apparently influence teachers' beliefs in both environments. This result also suggests that differences in teacher education program philosophy especially teachers from monoethnic environment preschools do influence teachers' curriculum beliefs and suggests that the current trend toward more college- level professional training for preschool teachers will move them towards stronger beliefs in child-initiated learning and multicultural practice.

About 95\% of the educators from both the monoethnic and multiethnic preschool environment use a variety of teaching strategies or techniques in inculcating multicultural practices. In multicultural classrooms, teachers hold high expectations for all students, and the use of a variety of pedagogy and learning activities reflects the teacher's commitment to providing equitable access for all students to the opportunity to achieve socially, vocationally, and academically. What, then, would be some of the pedagogy and learning activities in a classroom structured for the multicultural education practice of all children? Obviously there are many techniques that could be used with students over a period of time or within one instructional block. Additionally, different strategies make sense for different kinds of activities and knowledge-building opportunities, and the appropriateness of a given strategy to the content being taught is just as important as the use of a variety of methodologies. Some of the instructional strategies and activities that was implemented by educators from both the monoethnic and multi-ethnic preschool environment included the following: whole class and small group discussion, cooperative learning strategies, direct instruction, peer teaching or tutoring, children questioning, role play and simulations, interactive teaching, critical thinking or problem solving activities, panel discussions, inquiry-based activities, the use of manipulatives and learning centers, and activities geared to teaching children study, memorization, listening, coping, and test-taking strategies and skills. 
Obviously the use of these types of instructional strategies and activities requires the arrangement of a suitable physical environment and thoughtful instructional sequencing. Related to instruction and other areas requiring reflection are the teacher's view of knowledge construction, the socialized communication patterns of both children and teacher, teacher planning, and assessment. Children construct knowledge for themselves, usually based on the prior experience and prior knowledge they have relative to a subject. For example, the plight of an Indian child might be very difficult for a reader who has always lived in a Malay neighbourhood, to appreciate. In this regard, educators need to come to view themselves as facilitators of learning rather than as information givers. Children also come from cultural backgrounds that sometimes have produced in them greater facilitation with some types of communication strategies than with others. Thus, instruction needs to be reflective of an appreciation for this range of communication patterns children are likely to have mastered. All the educators agreed that in a multiethnic environment such strategies would be easier to integrate in teaching and learning.

\section{What Are the Issues and Challenges Facing Early Childhood Educators in Implementing Multiculturalism in a Monoethnic and Multiethnic Environment?}

In considering content, an educator's primary concern should be that of enabling children to develop an understanding of our collective history - the places in time and space where people's lives intersect but also the lives of groups of people prior to and after such intersections. Such an approach will allow children to fully understand the roles and contributions of various groups of people to human civilization and culture.

One critical challenge for educators in a multicultural curriculum is to include experiences that allow children to explore events, concepts, issues, and themes from multiple perspectives. These perspectives over time should be broad so that children don't end up inadvertently creating new stereotypes of different groups. Primary sources in the voices of the people they represent should be used as frequently as possible. Such an approach will help children to understand that one issue or event can be viewed in different ways by different people. A second important aspect of the curriculum is that it should be relevant to the lives of children and should reflect their images as well as their natural experiences. The content, therefore, should reflect everyday aspects of living and the daily experiences of children. This will sometimes create a necessity for educators to select illustrations, create analogies, or relate allegories that will connect new information to the experiences of the children. To do an effective job in this area, educators will need to develop their knowledge about the sociocultural backgrounds of their children. This is especially difficult if the preschool has a monoethnic environment.

All the educators in this research believe that a classroom environment needs to be a demonstration to children of the value the educator places on diversity. This means that instructional design, activities, interaction patterns, behaviours, and expectations must be fair and equitable for all. In a pluralistic society, educators need to be keenly aware that many of the traditional preschool patterns accommodate some children and work consistently against others. One example is interaction patterns. Some children learn communication style more indirect than direct; some children require thinking time before responding to a question; some children answer questions indirectly and give extraneous information in the process. Other elements that need examination include children mobility in the classroom, classroom organization, promotion of relationships (between a child and between a child and educator), use of tone (hopefully a positive one), and use of nonverbal communication, which frequently conveys more than verbal communication. Children from different culture may view a matter differently and this is one of the issues that preschool educators should tackle.

Overall, in the area of classroom climate, the classroom needs to be inviting, its decorations should reflect images and diversity of all the children, and the focus should be on active involvement of the child. 
We as educators, to be successful in this and other areas with diverse children populations, must examine our assumptions of what preschools and classrooms are supposed to be and do.

\section{Summary and Recommendations}

Each educator is a cultural being, one who has undoubtedly been socialized to see certain world views as valid and valuable. Educators learning about their own cultural orientation should recognize that otherstheir colleagues, children/students, parents - have also been socialized in these ways. Diverse populations mean that these others might have been socialized to see opposite views, values, and traditions as valuable and valid. It then becomes a duty of all engaged in the teaching and learning process to understand the importance of negotiation in creating a classroom environment comfortable for all even though it is a monoethnic and multiethnic preschool environment.

Many of us as educators have been taught to think that education is neutral and apolitical. As Gollnick (1990) reminds us, education is neither neutral nor apolitical. Every educational decision that is made at any level of education reflects someone's socialized world view and cultural orientation. If we are then to create classrooms and schools that are truly multiculturally sensitive, all elements and traditions that are a part of the schooling process must be examined and restructured even though it is a monoethnic and multiethnic preschool environment.

Educators committed to multiculturalism should consider implementing the ideas presented under the content, context, and teaching strategies sections of this article as well as the following.

o A curriculum that is antiracist and antisexist

o The promotion of critical consciousness in students and a curricular focus on social justice issues

o A multicultural curriculum that represents basic education for all children since they will all need this knowledge for success in their adult lives

o Multiculturalism as an on-going process that crosses all content areas and all other aspects of schooling

Preschool educators embracing multiculturalism will offer for some of their children the first opportunity to stand in the centre of life's stage. They will demonstrate that the democratic ideals on which this country was founded apply to their school life and to their personal lives. Multicultural education is an idea, an educational reform movement, and a process (Banks, 1997). As an idea, multicultural education seeks to create equal educational opportunities for all children, including those from different racial, ethnic, and social-class groups. Multicultural education tries to create equal educational opportunities for all students by changing the total preschool environment so that it will reflect the diverse cultures and groups within a society and within the nation's classrooms. Multicultural education is a process because its goals are ideals that teachers and administrators should constantly strive to achieve even though it is a monoethnic or multiethnic preschool environment.

\section{References}

Baldwin, S.C., Buchanan, A.M., \& Rudisill, M.E. (2007). What teacher candidates learned about diversity, social justice, and themselves from service-learning experiences. Journal of Teacher Education, 58 (4), 315-327. 
Banks, J. (1994). An introduction to multicultural education. Needham Heights, MA: Allyn and Bacon.

Bruch, P., Jehangir, R., Jacobs, W. \& Ghere, D. (2004). Enabling access: Toward multicultural developmental curriculum. Journal of Developmental Education, 27, 12-19, 41.

Creaser, B. (1996). Staff development: dealing with diversity. In B. Creaser and E. Dau (Eds.). The AntiBias Approach in Early Childhood. Sydney: Harper Educational.

Glover, A. (1996). Children and bias. In B. Creaser and E. Dau (Eds.). The Anti-Bias Approach in Early Childhood. Sydney: Harper Educational

Derman-Sparks, L. (1989). Anti-bias curriculum: Tools for empowering young children. Washington, DC: National Association for the Education of Young Children.

Derman-Sparks, L. (1993). Revisiting multicultural education: What children need to live in a diverse society. Dimensions of Early Childhood, 22(1), 6-10.

Early Childhood Australia National Council, 2007, available at http://www.earlychildhoodaustralia.org.au/position statements/cultural diversity.html ; accessed on 10 October 2007

Gollnick, D., \& Chinn, P. (1990). Multicultural education in a pluralistic society (3rd ed.). NewYork: Macmillan.

Gonzalez-Mena, J. (2000). Foundations - Early Childhood Education in a Diverse Society (2 ${ }^{\text {nd }}$ Ed.). New York: McGraw-Hill.

Goodall, H., Jacubowicz, A., Martin, J., Mitchell, T., Randall, L. \& Seneviratne, K. (1990). Racism, Cultural Pluralism and the Media. A Report to the Office of Multicultural Affairs, University of Technology, Sydney.

Hackman, H. (2005). Five essential components for social justice education. Equity and Excellence in Education, 38(2), 103-109.

Hakuta, K. (1986). Mirror of Language: The Debate on Bilingualism. New York: Basic Books.

Hohensee, J.B. \& Derman-Sparks, L. (1992). Implementing an anti-bias curriculum in early childhood classrooms. ERIC Digest. http://www.ericdigests.org/1992-1/early.htm

Lynch, E., \& Hanson, M. (Eds.). (1998). Developing cross-cultural competence: A guide for working with children and their families (2nd ed.). Baltimore: Paul H. Brookes.

Milner, D. (1983). Children \& Race, Beverly Hills, Calif: Sage Publications.

Oakes, J., \& Lipton, M. (2003). Teaching to change the world. New York: McGraw-Hill.

Palmer, G. (1990). Preschool children and race: an Australian study, Australian Journal of Early Childhood, vol. 15, (2), pp. 3-8.

Ramsey, P. \& Myers, L. (1990). Salience of race in young children's cognitive, affective and behavioral responses to social environments, Journal of Applied Behavioral Psychology, vol. 11, pp. 49-67.

Robinson, K. \& Jones Diaz, C. (2006). Diversity and Difference in Early Childhood Education. Berks: Open University Press. 
Sleeter, C. (2001). Preparing teachers for culturally diverse schools: Research and the overwhelming presence of whiteness. Journal of Teacher Education, 52(2), 94-106.

Stonehouse, A. (2002). NSW Curriculum Framework for Children's Services. NSW Department of Community Services. Office of Childcare. 